\title{
KNOWLEDGE AND AWARENESS OF CORONAVIRUS DISEASE-19 PROTOCOLS AMONG ANESTHESIA TECHNOLOGISTS AND TRAINEES IN WEST INDIA
}

\author{
SUJATA WALODE ${ }^{1}$, KARAN MORJE ${ }^{2}$, MOHAMMAD AKHLAQUE AHMAD ${ }^{2}$, MANNA DEBNATH ${ }^{3 *}$, SANTOSH OJHA $^{3}$ \\ ${ }^{1}$ Department of Operation Theatre and Anesthesia Technology, Symbiosis International University, Pune, Maharashtra, India. ${ }^{2}$ Department \\ of Operation Theatre and Anesthesia Technology, Charotar Institute of Paramedical Sciences, Charotar University of Science and \\ Technology, Anand, Gujarat, India. ${ }^{3}$ Department of Medical Imaging Technology, Charotar Institute of Paramedical Sciences, Charotar \\ University of Science and Technology, Anand, Gujarat, India. Email: mannadebnath93@gmail.com
}

Received: 11 May 2021; Revised and Accepted: 25 June 2021

\section{ABSTRACT}

Objectives: The main objective of the study is to assess the knowledge and awareness of all the anesthesia technologists and trainees regarding coronavirus disease (COVID-19) infection control protocols. The health and safety of anesthesia technologists are of great importance which can ultimately aid in minimizing the risk of infection among them and facilitate them to offer exceptional care to the patients.

Methods: This cross-sectional online survey was conducted on COVID-19 protocols using an online questionnaire that assesses the basic knowledge and awareness about infection control protocols. A total of 231 participant's responses were recorded using Google form and analyzed using the Statistical Package for the Social Sciences.

Results: The present study showed that participant's overall knowledge was good but they were not well trained on infection control protocol. Only $19.04 \%$ of participants were well trained about the protocol. The majority of the participants are well aware of the Personal Protective Equipment'srelated information.

Conclusions: To deal with this current situation, educational intervention on infection control protocol is urgently required to train Anesthesia technologists and trainees to defend against coronavirus.

Keywords: Coronavirus disease-19, Anesthesia technologists, Healthcare workers, Infection control protocols.

(C) 2021 The Authors. Published by Innovare Academic Sciences Pvt Ltd. This is an open access article under the CC BY license (http://creativecommons.org/ licenses/by/4.0/) DOI: http://dx.doi.org/10.22159/ajpcr.2021v14i8.42025. Journal homepage: https://innovareacademics.in/journals/index.php/ajpcr

\section{INTRODUCTION}

Coronavirus disease (COVID-19) has globally infected millions of populations, since its outbreak in Wuhan China, while India is one of the topmost countries to be infected by the COVID-19 infection. Healthcare workers are extremely vulnerable to the infection and have infected the normal population and many healthcare professionals [1]. The first initial case of COVID-19 was discovered in Wuhan, China, in late November 2019. Globally, there is widespread ongoing transmission of this virus to this date. Globally, COVID-19 has been reported with more than 102 million people infected with the virus, including more than 2.21 million deaths in 188 countries/regions currently whereas, India stands in the second position in COVID-19 confirmed cases. The singlestranded, RNA virus appears to be different but is related to other coronaviruses that cause severe acute respiratory syndrome- $\mathrm{CoV}$ and Middle East Respiratory Syndrome-CoV [2]. The route of transmission of COVID-19 is through respiratory droplets, contact with bodily fluids, or contaminated articles [3]. The main important symptoms of COVID-19 include fever, dyspnea, dry cough, fatigue, and myalgia [4]. Clinical presentation of COVID-19 represents, $80 \%$ of the patients infected are mild or asymptomatic, $15 \%$ of the patients infected are severe, and $5 \%$ of the patients infected are critical [5]. There is no specific antiviral agent that is approved for COVID-19 though some of the agents are used as treatment line which includes remdesivir, chloroquine, hydroxychloroquine, and lopinavir-ritonavir. To date, there is no vaccine invented for COVID-19. Therefore, to prevent this serious disease it is necessary to follow conventional infection control protocols and avoid unnecessary travel. Social distancing, appropriate use of Personal Protective Equipment's (PPE), and hand hygiene techniques should be followed thoroughly. Hence, supportive care is followed by medical centers worldwide to help alleviate the symptoms.
The incubation period for COVID-19 ranges from 2 to 14 days, according to the Centre for Disease Control (CDC) [6].

In general, anesthesia technologists and trainee take care of critically ill patients who are on ventilator support. An anesthesia technologist team has been working to provide care for severely ill COVID-19 patients to minimize the consequences of the fatal disease [7]. The anesthesia technologists and trainees are very helpful in assisting the anesthesiologist and are a part of the COVID-19 team. Today, anesthesia technologists also work in COVID centers in various hospital departments, including the operation theatre.

The infection rate was highest among the healthcare workers in the initial phase of the COVID-19 disease as there was no full knowledge of the disease concerning its methods of prevention and treatment [3]. Besides, a study showed that infected health care workers were one of the major factors involved in the spread of the disease [8]. As the anesthesia technologists are also working as frontline healthcare workers in this fight against COVID-19, it is crucial to ensure that these technologists are not only safe to protect the patients but also to make sure that they are not the source of transmission [3]. If we consider the importance of health care safety for anesthesia technologist personnel, we need to ensure their occupational safety. The knowledge and awareness toward COVID-19 are important in determining anesthesia technologist's promptness to actively participate and also accept the challenges of COVID-19 disease. Assessing the knowledge and awareness of COVID-19 would help to provide better insight into poor knowledge of this disease and the development of adequate training and infection control programs.

This study is essential for healthcare workers, in particular anesthesia technologists, because it adds to ongoing research to identify the 
infection control practices that they follow to help reduce the spread of infection and ensuring their safety as well. However, to date, there is relatively very limited published data on the awareness of knowledge and infection control protocols regarding COVID-19 among anesthesia technologists in West India. This study was done to evaluate the knowledge, awareness, and infection control practices among anesthesia technologists and trainees about COVID-19.

\section{METHODS}

This online survey was conducted during the mid-phase of the COVID-19 pandemic lockdown among anesthesia students and technologists. The survey questionnaire was structured to assess their knowledge of infection control protocols and awareness about COVID-19 between May 20, 2020 and August 20, 2020, using a self-administered online questionnaire. Participants with an education background in anesthesia technology (academic, clinical, industry, and research) and students of Operation Theatre and Anesthesia Technology were included in the study whereas other paramedical staff, students, and doctors were excluded. The questionnaire was prepared using Google form and was sent to the targeted group using different social media platforms for the collection of data. A convenient sampling technique was used for data collection. The questionnaire included three sections, the first section collects information on demographics, the second section was about knowledge-based questions, and the last and final section of the questionnaire was based on infection control practice. The aim of the research was well explained to the participants and their willingness to participate was documented in the first section of the questionnaire. The demographic variables include gender, education level, job experience and profession. A total of 17 questions about the knowledge and awareness protocols were included in the questionnaire. All the questions asked were closed-end questions, that is, yes-no response. Statistical analysis was performed using IBM Statistical Package for the Social Sciences Statistics for Windows, version 20.0 (IBM Corp., Armonk, N.Y., USA). All the questionnaires were tested for normality using the Kolmogorov Smirnov test. The data is following a normal distribution and further analysis was done using descriptive statistics.

\section{RESULT}

A total of 350 participants were requested to take part in the research study out of which 231 participants responded, most of the participants were female $56.3 \%(\mathrm{n}=130)$ and the remaining were males $43.7 \%(n=101)$. The majority of the participants had Undergraduate qualification $63.20 \%, 13.85 \%$ had Diploma, $11.69 \%$ were postgraduate and remaining $11.26 \%$ had undertaken certificate course in Operation Theater and Anesthesia Technology. The majority of the participants were having experience of $0-5$ years $(92.7 \%)$ followed by more than 15 years $(3.8 \%), 5-10$ years $(3 \%)$, and $10-15$ years $(0.4 \%)$. Most of the respondents were working in the clinical background $(61.04 \%)$ followed by academic (31.60\%), research (5.63\%), and industry $(1.73 \%)$. About $40.1 \%$ of participants responded that social media was one of the major platforms for spreading awareness about coronavirus followed by Newspaper/TV/Radio $36.32 \%$, seniors/colleagues $14.25 \%$, and $8.97 \%$ from Online workshops and seminars. The majority of the participants were from the orange zone $(36.80 \%)$ followed by the red zone $(35.05 \%)$ and the green zone (28.15\%) (Table 1$)$.

Almost $86.6 \%$ of respondents agreed that they knew about the coronavirus. However, only $11.3 \%$ of participants knew about the symptoms of the coronavirus and the rest $88.7 \%$ of the participants were unclear about the symptoms of the coronavirus. Most of the participants $(71.4 \%)$ were aware that there is less possibility of transmission of coronavirus through food and touch of animals. Around $43.7 \%$ of respondents had the wrong idea about the transmission of infection. The majority of the participants $(67.1 \%)$ think that antibiotics are the first line of treatment for this disease and $26.1 \%$ of participants think that the vaccine is available for coronavirus. Almost all the participants (93\%) knew about standard precautions for the prevention of infection by COVID-19 and also have sufficient knowledge (99.1\%) about the
Table 1: Demographic details of participants

\begin{tabular}{ll}
\hline Demographic Data & \\
\hline Characteristics & $\begin{array}{l}\text { Number of participants\% } \\
\text { (n=231) (\%) }\end{array}$ \\
& \\
\hline Gender & $101(43.7)$ \\
Male & $130(56.3)$ \\
Female & \\
Educational background of participants & 11.26 \\
Certificate & 13.85 \\
Diploma & 63.20 \\
Undergraduate & 11.69 \\
Postgraduate & \\
Experience of participants & 92.7 \\
0-5 years & 3 \\
5-10 years & 0.4 \\
10-15 years & 3.8 \\
More than 15 years & \\
Professions of participants & 61.04 \\
Clinical & 31.60 \\
Academic & 1.73 \\
Company & 5.63 \\
Research & \\
Source of information regarding & \\
COVID-19 & 40.10 \\
Social Media & 36.32 \\
Newspaper/TV/Radio & 14.25 \\
Seniors/Colleagues & 8.97 \\
Online workshops/seminars & 35.05 \\
Infection zone & 36.80 \\
Red & 28.15 \\
Orange & \\
Green & \\
\hline & \\
\hline & \\
\hline
\end{tabular}

PPE and $84.8 \%$ mentioned that it can't be reused. Participants had good knowledge about symptom identification, which they learned from different online webinars, conferences, and different social media applications. Around $8.7 \%$ of participants think that the infection with coronavirus always causes death. Almost all the participants (99.1\%) knew how to wear masks correctly. Around $74 \%$ of participants were well aware of donning and doffing protocol. It is observed that more than half of the participants responded well about the protocol of wearing masks and gloves, that is, only during the procedure with suspected COVID patients. When it comes to disinfection of hands, the majority of the participants perform hand hygiene techniques for visibly soiled hands. Almost $83.1 \%$ of participants agreed that for the patient with confirmed COVID-19 infection, the isolation room with the exhaust is necessary. $90 \%$ of the participants were very confident that they can participate in the care and the management of COVID-19 patients and $19.4 \%$ of respondents are trained with infection control protocols regarding COVID-19 (Table 2).

\section{DISCUSSION}

To the best of our knowledge, it is the first study on Anesthesia and Operation Theater technologists and students in West India for assessing knowledge regarding infection control in the COVID-19 situation. Improving the knowledge and awareness regarding infection control protocols of COVID-19 would encourage anesthesia technologists and students to maintain safety protocols. Globally, there is fear due to the rapid uprise of COVID-19 patients. In this situation, anesthesia technologists are considered as one of the prime frontline workers. Kotian et al. conducted a study focused on knowledge, attitude, and practice (KAP) in that $77.6 \%$ of participants held bachelor's degrees and $17.1 \%$ are having a master's degree in Medical Imaging Professionals [9]. Ojha et al. conducted a study on COVID-19 frontline workers in that majority of the participants were from the department of nursing followed by the department of medical imaging and radiology. Almost $67 \%$ of participants had a graduate degree and $18.2 \%$ of respondents held a post-graduate degree [10]. In the present study, 
Table 2: Responses of anesthesia students and technologists to knowledge on COVID-19

\begin{tabular}{|c|c|c|c|}
\hline \multicolumn{4}{|c|}{ Knowledge-based questionnaire } \\
\hline SN. & Questions & Yes & No \\
\hline 1. & $\begin{array}{l}\text { Have you heard about the } \\
\text { coronavirus? }\end{array}$ & $200(86.6 \%)$ & $31(13.4 \%)$ \\
\hline 2. & $\begin{array}{l}\text { Do you have knowledge about } \\
\text { the symptoms of a person with } \\
\text { suspected coronavirus (cough, } \\
\text { fever, shortness of breath, } \\
\text { extreme fatigue/Diarrhea)? }\end{array}$ & $26(11.3 \%)$ & $205(88.7 \%)$ \\
\hline 3. & $\begin{array}{l}\text { COVID-19 can transmit through } \\
\text { food or touch of animals? }\end{array}$ & $66(28.6 \%)$ & $165(71.4 \%)$ \\
\hline 4. & $\begin{array}{l}\text { People with severe symptoms } \\
\text { are the only ones to transmit the } \\
\text { infection? }\end{array}$ & $101(43.7 \%)$ & $130(56.3 \%)$ \\
\hline 5. & $\begin{array}{l}\text { Antibiotic is a first-line treatment } \\
\text { for COVID-19 disease? }\end{array}$ & $155(67.1 \%)$ & $76(32.9 \%)$ \\
\hline 6. & $\begin{array}{l}\text { Infection with coronavirus always } \\
\text { causes death? }\end{array}$ & $20(8.7 \%)$ & $211(91.3 \%)$ \\
\hline 7. & $\begin{array}{l}\text { Do you know about the standard } \\
\text { precautions for the prevention of } \\
\text { COVID - } 19 \text { infection and believe it } \\
\text { can prevent coronavirus? }\end{array}$ & $215(93 \%)$ & $16(6.9 \%)$ \\
\hline 8. & $\begin{array}{l}\text { Full form of PPE is Personal } \\
\text { Protective Equipment? }\end{array}$ & $229(99.1 \%)$ & $2(0.9 \%)$ \\
\hline 9. & Can you reuse PPE? & $35(15.2 \%)$ & $196(84.8 \%)$ \\
\hline 10. & $\begin{array}{l}\text { Do you know how to wear a mask } \\
\text { correctly? }\end{array}$ & $229(99.1 \%)$ & $2(0.9 \%)$ \\
\hline 11. & $\begin{array}{l}\text { Do you know about donning \& } \\
\text { doffing protocol? }\end{array}$ & $171(74 \%)$ & $60(26 \%)$ \\
\hline 12. & $\begin{array}{l}\text { Do you wear a mask and gloves } \\
\text { only during the procedure with } \\
\text { suspected COVID patients? }\end{array}$ & $118(51.1 \%)$ & 113 (48.9\%) \\
\hline 13. & $\begin{array}{l}\text { Do you frequently disinfect your } \\
\text { hand and perform hand washing } \\
\text { before and after contacting the } \\
\text { patients? }\end{array}$ & $223(96.5 \%)$ & $8(3.5 \%)$ \\
\hline 14. & $\begin{array}{l}\text { Preferred timing of hand hygiene } \\
\text { technique for visibly soiled hand } \\
\text { is } 30 \mathrm{~s} \text { ? }\end{array}$ & $201(87 \%)$ & $30(13 \%)$ \\
\hline 15. & $\begin{array}{l}\text { An airborne infection isolation } \\
\text { room (AIIR) with the exhaust is } \\
\text { recommended for the isolation } \\
\text { of that patient with confirmed } \\
\text { COVID-19 infection or those } \\
\text { under investigation? }\end{array}$ & $192(83.1 \%)$ & $39(16.9 \%)$ \\
\hline 16. & $\begin{array}{l}\text { Are you confident that you } \\
\text { can participate in the care and } \\
\text { the management of COVID-19 } \\
\text { patients? }\end{array}$ & $210(90 \%)$ & $21(9.1 \%)$ \\
\hline 17. & $\begin{array}{l}\text { Are you trained with infection } \\
\text { control protocols regarding } \\
\text { COVID-19? }\end{array}$ & $44(19.04 \%)$ & $187(80.95 \%)$ \\
\hline
\end{tabular}

the majority of the respondents, that is, $63.20 \%$ are undergraduate students and $61.04 \%$ are working clinically.

Alshammari et al. researched Saudi Arabia based on KAP on COVID-19 in which they stated that $49.5 \%$ of the respondents obtained information regarding coronavirus from social media followed by websites (25.3\%) and TV/Radio (23.1\%\%) [1]. Similarly in the present study, we found out that social media is the major source $(40.10 \%)$ from where participants get information about coronavirus followed by Newspaper/TV/Radio (36.32\%), seniors/colleagues (14.25\%), and online workshops/seminars (8.97\%). While nearly everyone nowadays has a smartphone and uses social media, staying up to date on this coronavirus is easier.
Maheshwari et al. conducted a study on medical students in which they reported that $86.7 \%$ of the participants agreed that the main clinical symptoms are cough, fever, fatigue, and $55.9 \%$ of participants also think that eating or contacting with wild animals would not result in the spread of the infection [12]. In the present study, only $11.3 \%$ of respondents have the proper knowledge of coronavirus symptoms, and similar to the previous study, $71.4 \%$ of participants denied the fact that COVID-19 can transmit through food or touch of animals. About $43.7 \%$ of participants responded that people with serious symptoms are the major source for the transmission of the virus, although recent studies suggest that even asymptomatic patients are responsible for the transmission of the virus. The participants lack the knowledge about the symptoms of coronavirus and had fair knowledge about the transmission of coronavirus.

The anesthesia technologists and trainees need to know about the standard operating protocol for the prevention of infection. According to the Centers for Disease Control and Prevention (CDC), standard precautions are a set of practices that are applied for the care of the patients in all healthcare facilities at all times [13]. Ikhlaq et al. performed a study based on awareness and attitude on undergraduate medical students in which $90.4 \%$ of participants agreed that coronavirus can be prevented by following the standard precautions set forth by the CDC [14]. In the present study, $93 \%$ of the respondents had a similar response.

PPEs are protective gear that is used to safeguard the healthcare workers by minimizing exposure to an infectious agent [15]. According to the study conducted by Ojha et al., they reported that participants responded positively when it comes to the disposal of PPE kits according to the standard guideline given by the Center for Disease Control and the management [10]. In the present study, the majority of the participants (84.8\%) agreed that PPE cannot be reused.

Xu et al. researched COVID-19 Knowledge, Awareness, and Attitudes found that $90.5 \%$ of students and $87.2 \%$ of medical staff agreed that a mask should be worn during the COVID-19 pandemic [16]. Maleki et al. performed a study focused on Knowledge, Attitude, and Behavior of Health Care staff in COVID-19, where $96.9 \%$ of respondents from the nursing department agreed that they wear face mask correctly and $42.9 \%$ of radiologist accept that they don't know how to wear face masks properly [3]. Similarly in the present study, $99.1 \%$ of participants agreed that they were aware of how to wear face masks properly. It is because during the procedure anesthesia technologists and trainees were always wearing masks inside the Operation Theater. Besides the information on the PPE and wearing masks, it is also important to know about the protocols of donning and doffing. Almost $74 \%$ of the participants were aware of the donning and doffing protocol.

Maleki et al. reported a study in which the majority of the nursing participants (93.8\%) frequently perform hand washing or disinfect their hands [3]. Similarly, in our study, $96.5 \%$ of participants perform hand washing frequently before and after touching the patients. The majority of the participants $(87 \%)$ responded correctly about the timing of hand hygiene for visibly soiled hands. Healthcare workers should frequently disinfect and perform hand hygiene. The Hand Hygiene method, which determines the moments when hand hygiene should be practiced by health care staff, has five moments namely before touching the patient, before aseptic operations, after body fluid exposure, after touching the patient, and after touching the surrounding the patient [17].

Almost $90 \%$ of participants are confident that they can actively participate in the care and the management of COVID-19 patients that shows that they are having the willpower to serve society in that critical situation. In the present study, only $19.4 \%$ of participants were trained with infection control protocol. Anesthesia technologists should be aware of the infection control protocols for COVID-19, due to its mode and rate of transmission. A similar result was also reported by Modi et al., Bhagavathula et al., and Lai et al. $[1,18,19]$. The lack of awareness 
and practices of infection prevention for COVID-19 and the risk of disease in healthcare workers were reflected in this study. The majority of the participants knew about the virus but were not aware of the infection control practices for COVID-19. Regular training and briefing are needed on knowledge and infection control protocols for anesthesia technologists.

\section{Limitation of the study}

There might be potential sampling bias as the number of responders was unequal for different demographic variables such as education qualification, work experience which will greatly impact the response of the participants. In this study we have used a self-reported questionnaire thus it might recall response bias in the study. No institutional review board was approached due to the COVID-19 lockdown.

\section{CONCLUSION}

The present study reveals that the anesthesia technologists and trainees are not fully aware of the pathophysiology of the COVID- 19 . They lack in-depth training regarding infection control protocol in the present scenario. From the findings of this study, we can conclude that regular training and briefing on infection control protocols are needed to mitigate the situation.

\section{ACKNOWLEDGEMENT}

We are thankful to the Symbiosis Institute of Health Sciences, Symbiosis International University, and Charotar Institute of Paramedical Sciences constituent of Charotar University of Science and Technology for their constant support and encouragement for conducting this survey study. We are thankful to all the Anesthesia technologists and students for participating in the survey.

\section{CONFLICTS OF INTEREST}

The authors declare that there are no conflicts of interest regarding the publication of this article.

\section{AUTHORS CONTRIBUTION}

Sujata Walode, Manna Debnath, Akhlaque Ahmad, and Santosh Ojha had contributed to the design of the study. Ms. Sujata Walode, Karan Morje, and Akhlaque Ahmad also contributed to the collection of the data. The analysis of raw data and its interpretation was done by Manna Debnath. Karan Morje and Santosh Ojha had scrutinized the article for quality content. Finally, all the authors have read and approved the manuscript.

\section{FUNDING}

The authors did not receive any funding for this research.

\section{REFERENCES}

1. Modi PD, Nair G, Uppe A, Modi J, Tuppekar B, Gharpure AS, et al. COVID-19 awareness among healthcare students and professionals in Mumbai metropolitan region: A questionnaire-based survey. Cureus 2020;12:e7514.

2. Wax RS, Christian MD. Practical recommendations for critical care and anesthesiology teams caring for novel coronavirus (2019-nCoV) patients. Can J Anesth 2020;67:568-76.

3. Maleki S, Najafi F, Farhadi K, Fakhri M, Hosseini F, Naderi M. Knowledge, Attitude and Behavior of Health Care Workers in the Prevention of COVID-19; 2020.

4. Pratinidhi SA, Sayyed AA, Tilokchandani MA, Malode SV, Bhalgat SS, Bhujbal CR. Awareness of COVID-19 outbreak in local population of Maval taluka in Maharashtra, India. Int J Res Med Sci 2020;8:2378-84.

5. World Health Organization. Coronavirus Disease 2019 (COVID-19) Situation Report-06 March. Geneva: World Health Organization; 2020. Available from: https://www.who.int/docs/default-source/coronaviruse/ situation-reports/20200306-sitrep-46-covid-19.pdf.

6. Sahu KK, Mishra AK, Lal A. COVID-2019: Update on epidemiology, disease spread and management. Monaldi Arch Chest Dis 2020;90:1292.

7. Dost B, Koksal E, Terzi Ö, Bilgin S, Ustun YB, Arslan HN. Attitudes of anesthesiology specialists and residents toward patients infected with the novel coronavirus (COVID-19): A national survey study. Surg Infect 2020;21:350-6.

8. Chang D, Xu H, Rebaza A, Sharma L, Cruz CS. Protecting health-care workers from subclinical coronavirus infection. Lancet Respir Med 2020;8:e13.

9. Kotian RP, Faujdar D, Kotian SP, D'Souza B. Knowledge and understanding among medical imaging professionals in India during the rapid rise of the covid-19 pandemic. Health Technol 2020;10:1415-20.

10. Ojha S, Debnath M, Sharma D, Niraula A. Knowledge of handling the personal protective equipment (PPE) by frontline allied health professionals in COVID-19 outbreak a web-based survey study. J Radiol Nurs 2020;40:167-71.

11. Alshammari F, Alhagbani T, Alafnan A, Almansour K, Khan K. Knowledge, attitudes, and practices towards covid-19 among residents in hail city, Saudi Arabia: A cross-sectional study. Asian J Pharm Clin Res 2020;13:147-52.

12. Maheshwari S, Gupta PK, Sinha R, Rawat P. Knowledge, attitude, and practice towards coronavirus disease 2019 (COVID-19) among medical students: A cross-sectional study. J Acute Dis 2020;9:100.

13. Centers for Disease Control and Prevention. Interim Infection Prevention and Control Recommendations for Healthcare Personnel during the Coronavirus Disease 2019 (COVID-19) Pandemic. Atlanta, Georgia: Centers for Disease Control and Prevention; 2020.

14. Ikhaq A, Bint E, Riaz H, Bashir I, Ijaz F. Awareness and attitude of undergraduate medical students towards 2019-novel corona virus. Pak J Med Sci 2020;36:S32-6.

15. Novel Coronavirus Disease 2019 (COVID-19): Guidelines on Rational Use of Personal Protective Equipment; Ministry of Health and Family Welfare; Directorate General of Health Services. Available from: https://www.mohfw.gov.in/pdf/ GuidelinesonrationaluseofPersonalProtectiveEquipment.pdf.

16. Xu H, Mendez MJ, Guo L, Chen Q, Zheng L, Chen P, et al. Knowledge, awareness, and attitudes relating to the COVID-19 pandemic among different populations in Central China: Cross-sectional survey. J Med Intern Res 2020;22:e22628.

17. World Health Organization. Hand Hygiene: Why, How and When? Geneva: World Health Organization; 2009. Available from: https:// www.who.int/gpsc/5may/hand hygiene why how and when brochure.pdf.

18. Bhagavathula AS, Aldhaleei WA, Rahmani J, Mahabadi MA, Bandari DK. Knowledge and perceptions of COVID-19 among health care workers: Cross-sectional study. JMIR Public Health Surveill 2020;6:e19160.

19. Lai X, Wang X, Yang Q, Xu X, Tang Y, Liu C, et al. Will healthcare workers improve infection prevention and control behaviors as COVID-19 risk emerges and increases, in China? Antimicrob Resist Infect Control 2020;9:1-9. 